\title{
Morphological Features of the Popliteus Tendon, Popliteofibular and Lateral (Fibular) Collateral Ligaments
}

\author{
Características Morfológicas del Tendón del Músculo Poplíteo, \\ y Ligamentos Popliteofibular y Colateral Fibular
}

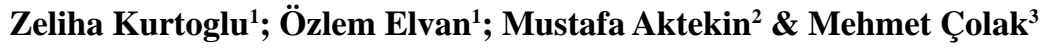

KURTOGLU, Z.; ELVAN, O; AKTEKIN, M. \& ÇOLAK, M. Morphological features of the popliteus tendon, popliteofibular and lateral (fibular) collateral ligaments. Int. J. Morphol., 35(1):62-71, 2017.

SUMMARY: To reveal the detailed morphological features of the fibular collateral (fibular) ligament, popliteus tendon, popliteofibular ligament and the synovial components regarding to achieve data for surgical and biomechanical utilization. Knees of 10 formalin-fixed male cadavers were dissected bilaterally. Bursae around the lateral collateral ligament and the relation of popliteus tendon with lateral collateral ligament at the femoral attachment site were noted. The positional relation between both ends of popliteofibular ligament was evaluated statistically. The PT exceeded the anterior margin of lateral collateral ligament in 11 sides, the posterior margin of lateral collateral ligament in 3 sides and exceeded both the anterior and posterior margins of lateral collateral ligament in 5 sides. The shape of lateral collateral ligament was narrower at the lower part than the upper in 14 sides. The width of lower part of lateral collateral ligament was found narrower in the cases with sheath-like bursa (vagina synovialis). The relation between both ends of popliteofibular ligament was as followed: the more anteriorly the fibular head attachment was located, the more anteriorly popliteofibular ligament was attached to the popliteus tendon. To resolve the posterolateral corner of the knee with regard to surgical anatomy and biomechanics, individual and concerted morphometric characteristics of lateral collateral ligament, popliteus tendon and PF should be evaluated together with accompanied synovial structures.

KEY WORDS: Lateral (fibular) collateral ligament; Popliteus tendon; Popliteofibular ligament; Synovial; Knee;

\section{INTRODUCTION}

Considering the surgical and functional importance of the posterolateral corner of the knee (PLC), in recent years there has been increasing interest in the region. Injuries of PLC are surgically important as playing major role against varus rotation, external rotation and posterior tibial translation (LaPrade et al., 2003; Brinkman et al., 2005; Espregueira-Mendes \& da Silva, 2006 \& James et al., 2015). Among the numerous lateral structures of the knee, the lateral (fibular) collateral ligament (LCL), popliteus tendon (PT) and popliteofibular ligament (PF) are the key structures for posterolateral stability (LaPrade et al.).

Despite its clinical significance, injuries of PLC could be still undiagnosed, and left untreated clinically due to its complex structuring and variations in anatomy (LaPrade $e t$ al.; Covey, 2001 \& Zeng et al., 2011). The lack of reconstruction of the PLC structures causes the failures of surgery and residual instability of the knee (James et al.; Covey; Jung et al., 2010 \& Djian, 2015). Additionally, inconsistency in nomenclature of the ligamentous structures of the region (the fabellofibular ligament, arcuate popliteal ligament (AL) and PF) makes the area more difficult to cope with. The discrepancies for these ligaments have already been tried to be clarified by several authors and also the authors of previously presented study (Seebacher et al., 1982; Osti et al., 2013 \& Kurtoglu et al., 2015). For the PLC injuries, many reconstruction techniques have been published in the literature (Djian; Jung et al.; Niki et al., 2012 \& Minowa et al., 2005). Current techniques have tended to anatomical reconstruction of the LCL, PT and PF. Many authors proposed that grafts must conform to the natural anatomy of attachment sites in terms of length and its original anatomical locations (LaPrade

\footnotetext{
${ }^{1}$ Mersin University Faculty of Medicine, Department of Anatomy, Mersin, Turkey.

${ }^{2}$ Acıbadem University School of Medicine, Department of Anatomy, Istanbul, Turkey.

${ }^{3}$ Mersin University Faculty of Medicine, Department of Orthopedics, Mersin, Turkey.
} 
et al.; Jung et al. \& Zeng et al.). Femoral attachment sites of LCL and PT and the attachments of PF to PT and fibular head $(\mathrm{FH})$ were also indicated as important issues in posterolateral anatomic reconstruction techniques (Jung et al.; James et al.; Takeda et al., 2015). Besides, the synovial components around the LCL, which could have importance regarding the surgical and biomechanical features of the ligament, were poorly mentioned in the literature.

In this study, it was aimed to reveal the detailed morphological features of LCL, PT and PF, and the synovial components of those structures regarding to achieve data for surgical and biomechanical viewpoint.

\section{MATERIAL AND METHOD}

The study was carried out on the cadavers obtained in accordance with institutional and legal procedures and preserved in Anatomy Department of Mersin University. The authors declare that they performed the study in accordance with the provisions of the Declaration of Helsinki 1995 (as revised in Edinburgh 2000). Posterolateral corner of both knees in 10 formalin-fixed male cadavers (aged between 45 -104 years, average $66.89 \pm 18.92$ ) were dissected. (All dissections were performed bilaterally and knees were in extended position. Biceps femoris and plantaris muscles and the lateral head of gastrocnemius were removed.
Measurements for all structures were performed by the same researcher. Linear measurements were done with digital caliper ( $0.01 \mathrm{~mm}$ precision). Values are given as mean and standard deviations.

Lateral (fibular) collateral ligament: After determining the shape, length, midpoint width and thickness of LCL, it was cut from its midpoint and separated into upper and lower parts (Figs. 1, 2a, b). Then widths and thicknesses of these parts were measured at their midpoints. Location and length of the synovial components around the LCL were noted. A sheath-like bursa surrounding both the superficial and deep aspect of the LCL was described as 'vagina synovialis'. The relation of LCL and the biceps femoris tendon was identified (Figs. 3a-c).

Popliteus tendon: The positional relationship of femoral attachments of PT and LCL was demonstrated as Figs. 4ad. The PT length was measured as the distance from the attachment of lateral epicondyle to the popliteus muscle tendon junction (PMTJ) by using a flexible wire. It was transected just above the lateral meniscus. Thickness and widths of PT were measured from the upper part and at the level of articular line. Relation of PT with synovial membrane was noted as being extrasynovial or partially intrasynovial: When the main joint space continued between the capsule and outer surface of PT partially as making a recess, it was defined as partially intrasynovial PT (Figs. $5 a, b)$.

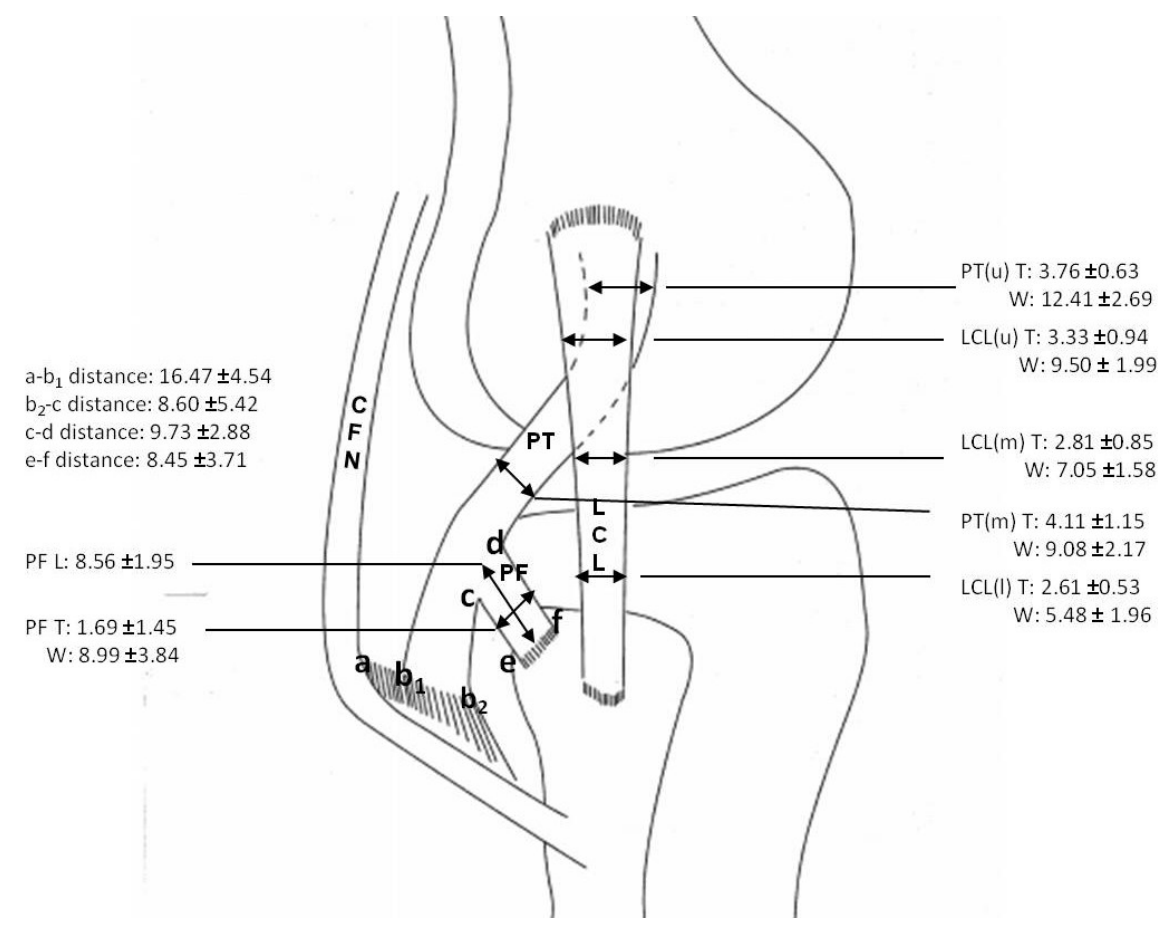

Fig. 1. Schematic drawing showing the measurements about the LCL, PT and PF (values are given in $\mathrm{mm}$ ). a-b1: the width of capsular attachments of popliteus muscle, b2-c: the distance between popliteus muscle tendon junction and the PF, c-d: PF attachment width to the PT, e-f: PF attachment width to the fibular head, T: thickness, W: width, L: mid-length of the PF, $\mathrm{u}$ : upper part, m: middle part, 1 : lower part, LCL: lateral collateral ligament, PT: popliteus tendon, PF: popliteofibular ligament. 

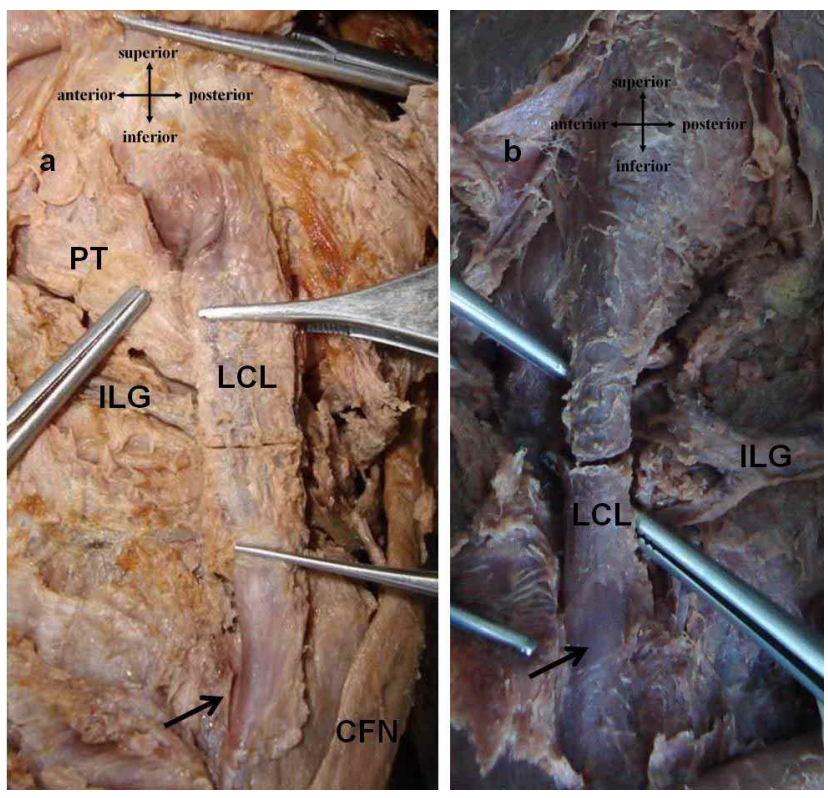

Fig. 2. Photographs showing the shapes of LCL. a) The upper part of LCL is wider than the lower part. Black arrow: bursa between the LCL and biceps femoris as a vagina synovialis formation, b) LCL is in a band-like shape. Black arrow: bursa between the LCLbiceps femoris as a sac formation. ILG: inferior lateral genicular vessels, LCL: lateral collateral ligament; $\mathrm{CFN}$ : common fibular nerve, PT: popliteus tendon

Popliteofibular ligament: In accordance with the previous guidance of Kurtoglu et al., the PF has been distinguished from the deep part of AL by taking into account their attachment sites. The width and thickness of PF at its midpoint and its midline length were measured (Fig. 1) and its geometric shape was defined. The widths of PF attachments on PT and styloid process (SP) were evaluated. The course of PF was noted, and then its attachment sites to the PT and FH were evaluated (Figs. 6a, b). The relation of PF with popliteus was assessed whether it attached to the muscular or tendinous part of the muscle.
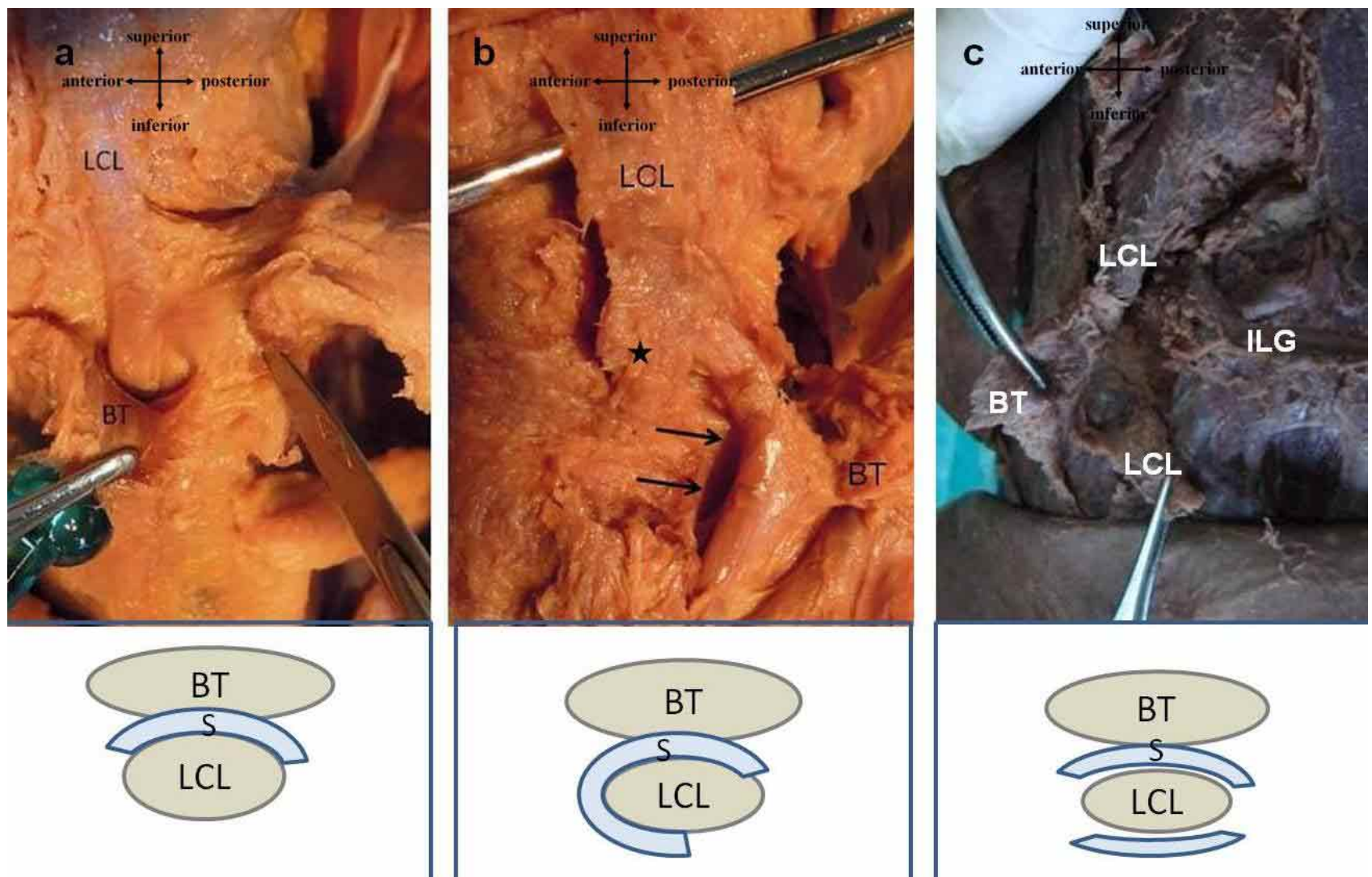

Fig. 3 Types of bursa around the lower part of LCL are demonstrated by photographs and schematic drawings for the transverse section. a) Bursa locating at the superficial aspect of LCL as a sac formation. b) Bursa covering the anterior, superficial and deeper portions of LCL, as a vagina synovialis formation; the black arrow: the deeper portion of the synovial sac. Black star: the dense fibrous extensions leaving from the LCL and merging with the capsular fibrous tissue. c) The lower part of LCL was retracted downwards and the bursa lying deep to LCL was shown with white arrows. LCL: lateral collateral ligament; BT: biceps femoris tendon; ILG: inferior lateral genicular vessels, S: synovial formation. 
Statistical Methods: Normal distribution of the variables was examined by Kolmogorov-Smirnov test. Paired t test was used to evaluate difference between the parts of LCL and between the sides regarding the morphometric measurements of LCL, PT and PF. No difference was found between the sides for those parameters. Descriptive statistics were given in Table I. Independent samples t-test was used to access difference between the groups with bursa and vagina synovialis regarding the LCL measurements.

Any relationship between the attachment sites of PF onto PT and FH was statistically evaluated: Spearman correlation test was used to assess the relationship between the attachment sites (Fig. 6). A p-value of less than 0.05 was considered to be statistically significant.
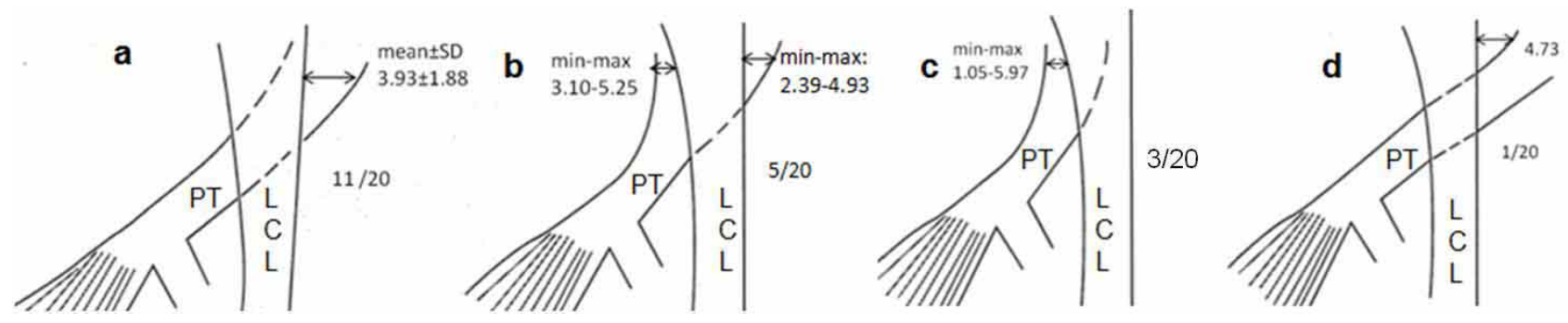

Fig. 4. Variations in the positional relation of LCL and PT at the femoral attachment site. a) PT partially exceeded the anterior margin of LCL. b) PT exceeded both the anterior and posterior margins of the LCL. c) PT exceeded the posterior margin of the LCL. d) PT attached completely anterior to the LCL. Arrow: the distance between the LCL and PT attachment. PT: popliteus tendon, LCL: lateral collateral ligament (values were given in $\mathrm{mm}$ ).
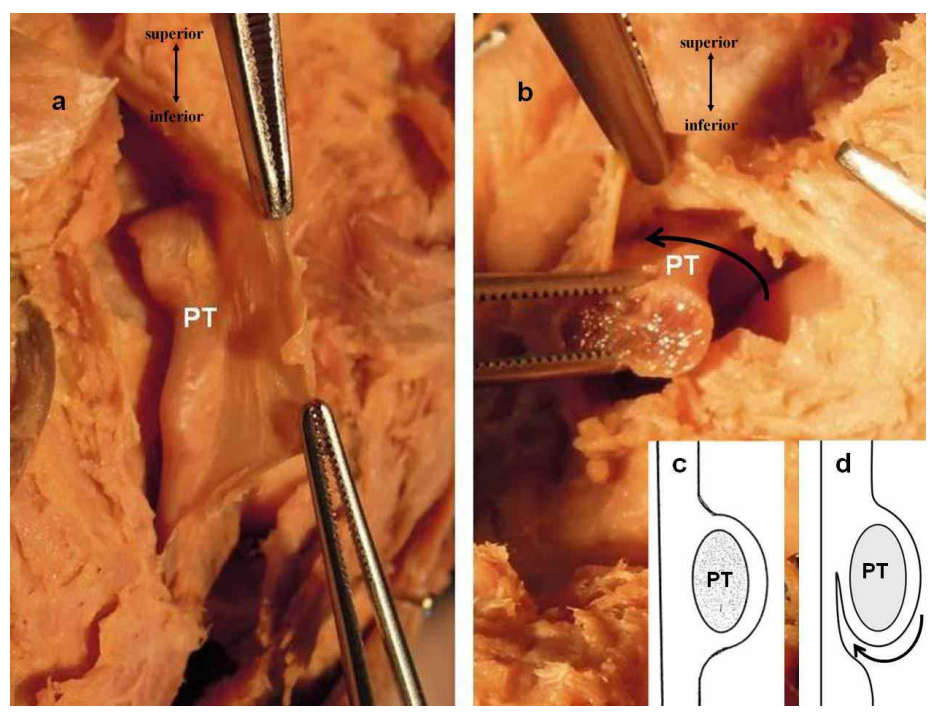

Fig. 5. Photographs of the case in which the popliteus tendon (PT) was coursing as intraarticular and partially intrasynovial at the level of the articular line. a) Capsule was retracted downward, and the synovial membrane partially covering the posterior part of PT was revealed b) PT was transected together with the capsule at the level of the articular line c) the normal appearance of PT, d) partially intrasynovial popliteus tendon (PT), curved arrow: synovial recess behind the PT.

\section{RESULTS}

Lateral (fibular) collateral ligament: Two types of LCL were identified regarding to its shape (Fig. 2). In 14 sides, the upper part was markedly wider than the lower part (i.e. difference between the width of upper and lower parts was more than $3 \mathrm{~mm}$ ). In 6 sides, shape of LCL was like a band (i.e. difference between the parts was less than $3 \mathrm{~mm}$ ).

Dense fibrous extensions leaving from the LCL and merging with the capsular fibrous tissue were more or less observed in all cases. Accordingly, when compared with paired $t$ test, the width of LCL was found significantly getting narrower gradually from proximal to distal (for the upper part and midpoint $\mathrm{p}=0.001$, for the upper and lower parts $\mathrm{p}=$ 0.001 and for the midpoint and lower part $\mathrm{p}=0.013$ ). Also, regarding its thickness, the upper part was found significantly thicker than the midpoint and the lower part (for the upper and midpoint $\mathrm{p}=0.001$ and for the upper and lower parts $\mathrm{p}=0.004$ ) (Table I), (Fig. 1).

The inferior part of LCL was covered by the superficial extension of the biceps femoris tendon. We observed a synovial bursa around the lower part of LCL in 18 sides. In 9 out of 18, it was located superficial to the LCL as a sac (with an average height of $10.83 \pm 3.35 \mathrm{~mm}$, ranged between $3.90-15.60 \mathrm{~mm}$ ) (Fig. $3 a)$. In 4 of those cases, an additional bursa, independent from the superficial one, was found deep to LCL (Fig. 3c). While in the other 9 sides, a synovial sheath was covering the superficial surface, anterior 
margin and the deep surface of distal part of LCL like a vagina synovialis (with an average height of $13.79 \pm 4.25 \mathrm{~mm}$, ranged between 10.55-23.80 mm) (Fig. 3b). At the cases with vagina synovialis, it was observed that the posterior margin of LCL was the more intensely fused with the intermediate part of BT.

The lower part width of LCL was found narrower in the cases with a vagina synovialis than those with a bursa by independent samples t-test $(\mathrm{p}=0.006)$.

Popliteus Tendon: Measurements of the PT were given in Table I and shown in Fig. 1.

The width of PT at the upper part was significantly greater than that of the level of articular line $(\mathrm{p}=0.001)$, but there was no significant difference in thickness $(\mathrm{p}=0.157)$.

PT began from PMTJ passed deep to the LCL and $\mathrm{AL}$, and then attached to the femoral epicondyle in close relation with the LCL attachment. Observations about the various positional relations of LCL and PT were classified and demonstrated in Figs. 4a-d. In 11 sides, the PT attachment exceeded the anterior margin of the LCL. In 3 sides, the PT attachment exceeded the posterior margin of the LCL. In 5 sides, the PT attachments exceeded both the anterior and posterior margins of LCL. In only one side the whole PT attachment was just anterior to the LCL attachment.

PT has been described as intra-capsular and extrasynovial in the literature (Feipel et al., 2003; Kim et al., 2009). However, in 5 cases, upper part of PT was found partially intrasynovial. In one of those cases, PT was also continued as partially intrasynovial at the level of the articular line (Figs. 5a and b). Bifurcated PT was not encountered in any case. While, in only one case, PT seemed bent on its own, as the separated superficial and deep parts of the PT continued with each other at the anterior edge.

All but one cadaver, it was observed that the medial part of the popliteus muscle fibers was merged with the capsule along a line just superomedial to the PMTJ (Table I). In only one cadaver, capsular attachment was absent on both sides.

Popliteofibular ligament: The PF was identified in all sides. The PF originated from SP and attached to the lower margin of PT. Three different geometrical types of PF have been described: Type 1; PF had a band shape in 14 sides. Type 2; PF had a narrower fibular attachment and a larger PT attachment which gave it a truncated cone shape, in 5 sides. Type 3; named as reverse truncated cone shape and was observed in only one side. Measurements of the PF as length, thickness and widths were given in Table I and were shown in Figure 1. According to Pearson correlation test, there were negative relationships of PF's width with both PF length $(\mathrm{p}=0.008, \mathrm{r}=-0.587)$ and thickness $(\mathrm{p}=0.011, \mathrm{r}=-0.554)$.

The attachments of $\mathrm{PF}$ on $\mathrm{FH}$ and $\mathrm{PT}$ were categorized as Figures 6a, b. The attachment of PF on FH was defined regarding its position to SP apex (Fig. 6a): in 12 sides, it was at the apex (in 1 side the anterior slope and apex, in 5 sides the posterior slope and apex, in 6 sides centered to apex). In 4 sides it was totally on the anterior slope of SP, and in another 4 sides, it was totally on the posterior slope of SP.

Table I Descriptive statistics regarding the morphometric measurements of LCL, PT and PF (n:20 sides)

\begin{tabular}{|c|c|c|c|c|c|}
\hline & Measurement & in $(\mathrm{mm})$ & $\operatorname{Max}(\mathrm{mm})$ & $\operatorname{Mean}(\mathrm{mm})$ & SD \\
\hline Lateral (fibular) collateral ligament (FCL) & Length & 46.30 & 68.70 & 59.76 & 5.58 \\
\hline \multirow{2}{*}{ Upper part } & Width & 5.93 & 13.85 & 9.50 & 1.99 \\
\hline & Thickness & 1.89 & 6.02 & 3.33 & 0.94 \\
\hline \multirow{2}{*}{ Middle part } & Width & 4.78 & 9.90 & 7.05 & 1.58 \\
\hline & Thickness & 1.39 & 5.41 & 2.81 & 0.85 \\
\hline \multirow{2}{*}{ Lower part } & Width & 2.71 & 9.49 & 5.48 & 1.96 \\
\hline & Thickness & 1.77 & 3.54 & 2.61 & 0.53 \\
\hline Popliteus tendon (PT) & Length & 31.90 & 63.10 & 43.74 & 8.30 \\
\hline \multirow[t]{2}{*}{ Upper part } & Width & 8.12 & 17.45 & 12.41 & 2.69 \\
\hline & Thickness & 2.45 & 4.60 & 3.76 & 0.63 \\
\hline \multirow{2}{*}{ Middle part (at the level of articular line) } & Width & 5.41 & 12.98 & 9.08 & 2.17 \\
\hline & Thickness & 1.67 & 6.66 & 4.11 & 1.15 \\
\hline \multirow[t]{3}{*}{ Capsular attachment of popliteus muscle } & Width & 7.70 & 25.0 & 16.47 & 4.54 \\
\hline & Length & 5.70 & 12.30 & 8.56 & 1.95 \\
\hline & Width & 1.36 & 16.50 & 8.99 & 3.84 \\
\hline \multirow[t]{3}{*}{ Popliteofibular ligament (PF) } & Thickness & 0.40 & 6.43 & 1.69 & 1.45 \\
\hline & Attachment width to PT & 7.00 & 17.20 & 9.73 & 2.88 \\
\hline & Attachment width to fibular head & 3.00 & 15.40 & 8.45 & 3.71 \\
\hline
\end{tabular}




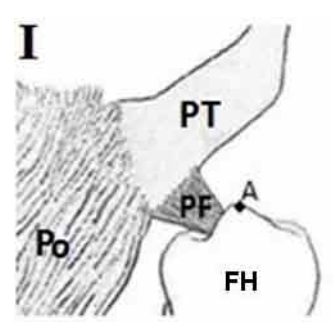

(a) $4 / 20$

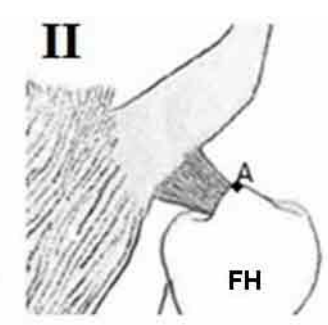

$5 / 20$

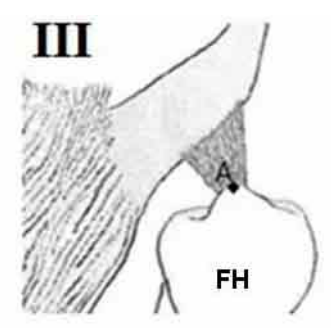

$6 / 20$

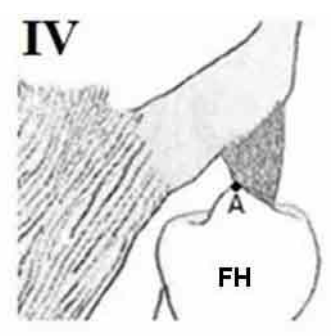

$1 / 20$

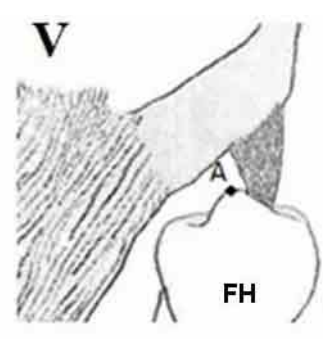

$4 / 20$

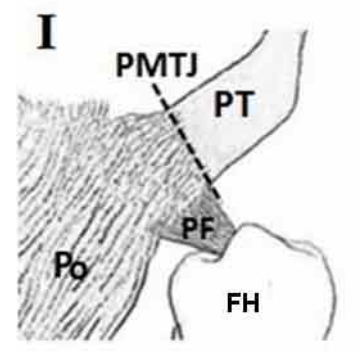

(b)

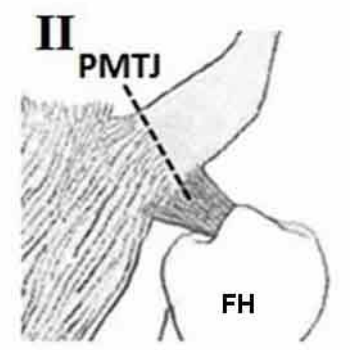

$2 / 20$

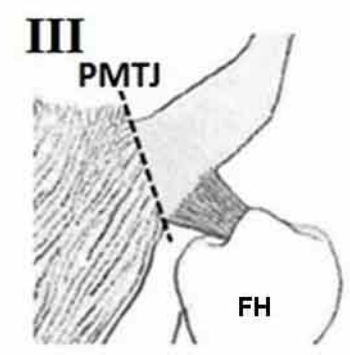

$8 / 20$

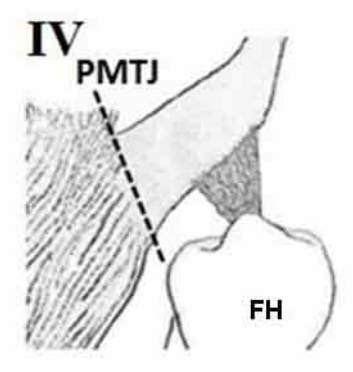

$8 / 20$

Fig. 6: a) Variations in the popliteofibular ligament (PF) attachment on FH. (I) PF attached on the posterior slope of the styloid process (SP) distant to the apex (A), (II) PF attached to posterior slope of SP and apex, (III) PF attached to the apex, (IV) PF attached to the anterior slope of SP and apex, (V) PF attached on the anterior slope of SP distant to the apex. b) Variations in the position of the PF attachment to the popliteus muscle and/or tendon. (I) PF totally attached to the muscle proximal to PMTJ, (II) PF attached both to the muscle and PT, (III) PF attached to the PT as beginning from the PMTJ line, (IV)PF attached to PT distant to the PMTJ. PT: popliteus muscle tendon, Po: popliteus muscle; FH: fibular head; A: apex of styloid process; PMTJ: poplitealmusculotendinous junction.

The attachment site of PF on popliteus muscle and/ or tendon was assessed (Fig. 6b); in 8 sides, PF was attached to the tendon with a distance range of $2.00-18.20 \mathrm{~mm}$ to PMTJ. In 8 sides, PF was attached to the PT without any distance from PMTJ. In 2 sides, PF attached both on the tendon and muscle. In 2 other cases, PF attachment was totally on the muscle.

There was significantly positive relationship between the attachments of PF on FH and PT by Spearman correlation test $(\mathrm{p}=0.001)$ : The more anteriorly the FH attachment was located, the more anteriorly PF was attached to the PT.

\section{DISCUSSION}

Lateral (fibular) Collateral Ligament: The aim of the surgical procedure of injured LCL is to restore its natural anatomy and biomechanics because of the importance of LCL as being one of the static stabilizers of the PLC (Kim et al.). The present study supplies detailed data about multiple elements (i.e. size and synovial relationships) of the LCL that would affect the biomechanical properties of the ligament.

Our finding about the length of LCL was similar to previous studies, as shown in Table II (Maynard et al., 1996; LaPrade et al.; Ishigooka et al., 2004; Espregueira-Mendes \& da Silva; Zhang et al., 2009; Jung et al.; Osti et al.). In most of the cases, LCL was wider at the upper part and narrower at the lower part, in accordance with the findings of Takeda et al. In these literatures, width of LCL was given from the midportion or at the level of articular line. Our results revealed that there was significant difference between the upper and lower parts of the LCL regarding both width and thickness. Difference in the morphometric features of the upper and lower parts can be a factor that may affect the biomechanical properties of the knee and was suggested to be considered when reconstruction is planned. The slimming down of the ligament could be explained by fibrous extensions leaving from the LCL and spreading onto the capsule. Those extensions were interpreted to serve as anchors for the LCL and may disperse the uploaded weight onto the capsular fibrous tissue. 
Another factor that would be important during the surgery is bursa around the LCL. James et al., stated that the distal LCL attachment can be accessible through a small longitudinal incision to the bursa during LCL repair or reconstruction or total PLC reconstruction. Keeping in mind the variations about bursa formation could provide convenience during the PLC surgery. Regarding the presence and form of bursa, the cases were evaluated in four types as absent, sac form lying superficial to LCL, vagina synovialis form and bursa lying deep to LCL. Even though the presence of a LCL-biceps femoris bursa was mentioned (LaPrade \& Hamilton, 1997; Brinkman et al.; Espregueira-Mendes \& da Silva; Song et al., 2014) a vagina synovialis which embraced superficial, anterior and deep surfaces of the distal part of LCL has not been mentioned enough in the literature, except one (Fig. 3b). LaPrade \& Hamilton described a J shaped bursa around the anterior and anteromedial portions of the LCL, and they found it in all cases. That definition corresponds to vagina synovialis form as defined in this study and we found this type in 9 of 20 sides. In the presence of vagina synovialis, it was interesting to observe that the intermediate part of the biceps tendon was strictly fused with the posterior part of LCL along the synovial sheath. On the other hand, a deeply settled bursa accompanied by the superficial one independently was found in 4 sides. This type has not been mentioned by Laprade \& Hamilton but noted by Pansky \& Gest (2011).

The larger bursa surface could result in less friction for LCL. However, it is still unclear whether any reflection of the larger bursa to the morphometric features of LCL or not. We found that width of the lower part of LCL was narrower in the case with vagina synovialis than the case with bursa. Besides, further studies are needed to reveal the functional effects and clinicopathologic role of the variations of these bursae.

Popliteus Tendon: Morphometric features of the PT and its positional relation with LCL take great importance in PLC reconstruction. The results of our study are similar to the studies shown in Table II, except one; the PT length was found longer in the study of LaPrade et al., Zeng et al., stated that difference in the dimensions may be due to the race or the techniques used for measurement.

In most of the studies, the width and thickness of PT was measured from the level of the articular line (Table II). According to our observations, the PT seemed round in shape at the level of meniscus, then it was slightly widened upward. The results of the statistical analysis also supported that the width of upper part was significantly greater than the middle part. That finding could be taken into account when evaluating MR images of the tendon and planning any reconstruction procedure which appropriate to natural anatomy of PT. Widening of PT upward was not accompanied with any redu- ce in thickness. It is proposed that it could be explained by the change in fiber density, which needs further studies.

One of the most important findings of this study is about the positional relationship of LCL and PT at femoral attachment site which is important in posterolateral anatomic reconstruction techniques (Jung et al.; James et al.; Takeda et al.). Location of ligament footprints has been reported to be helpful for PLC for graft position, graft orientation and selection of tunnel position and diameter (Jung et al.; Osti et $a l$.). The attachment sites of LCL and PT on femoral condyle in the literature markedly varied. It was stated that PT attached 0.84-18.5 mm anterior to the LCL (Bartonícek, 2005; Brinkman et al.; Kim et al.). In some other studies, PT has been expressed to locate in three positions: posteroinferior, just inferior or posterior to the LCL in extension position of the knee (Ullrich et al., 2002; Zhang et al.; Jung et al.). Additionally, in the study of Zeng et al., it was stated that PT was overlapped by LCL. According to our findings, in 11 cases PT exceeded the anterior margin of LCL, while in 3 cases it exceeded posterior margin of LCL. In 5 cases PT lied beyond both anterior and posterior margins of LCL. In only one case, PT was totally placed $4.73 \mathrm{~mm}$ anterior to LCL (Fig. 4d).

Another remarkable issue of the region is the relation of synovial membrane with PT. In 5 cases, we found the femoral attachment of PT as intracapsular and partially intrasynovial (Fig. 5). In one of those cases, PT was also partially intrasynovial at the level of meniscus. But we have not encountered any description about the subject in the literature. PT can be teared in its midportion and any partial tear has been reported to manifest as fluid signal within the structure in the MRI (Recondo et al., 2000; Guha et al., 2003; Hash, 2013). In the partially intrasynovial PT cases, it was suggested that the synovial fluid behind the PT could be incorrectly interpreted as a tear of tendon. A common PT variation was reported as bifurcation of the PT (Tyler et al., 2010). We did not encounter any totally separated PT bundles. While, in one case, it was remarkable that the superficial and deep parts of PT were partially separated, the deep part was intrasynovial and there was a synovial recess between the parts.

The upper edge of the medial portion of the popliteus muscle serves as a landmark. Variation of this portion has been reported to complicate the surgery (Bartonícek). From this point, being aware of the presence and width of these fibers may be useful for orientation to the area during surgery. Feipel et al., documented the detailed features of capsular attachment of popliteus muscle and suggested that it might support posterolateral knee joint capsule. In the present study, in 18 of 20 cases, the upper-medial part of the popliteus muscle terminated by attaching to the posterior capsule of the knee joint. 
Table II Data for LCL, PT and PF in literature and the present study

\begin{tabular}{|c|c|c|c|c|c|c|}
\hline & \multicolumn{2}{|c|}{ FCL } & \multicolumn{2}{|c|}{ PT } & \multicolumn{2}{|l|}{ PF } \\
\hline & $\begin{array}{c}\text { Length } \\
(\mathrm{mm})\end{array}$ & $\begin{array}{l}\text { Width } \\
(\mathrm{mm})\end{array}$ & $\begin{array}{c}\text { Length } \\
(\mathrm{mm})\end{array}$ & $\begin{array}{l}\text { Width } \\
(\mathrm{mm})\end{array}$ & $\begin{array}{c}\text { Length } \\
(\mathrm{mm})\end{array}$ & $\begin{array}{r}\text { Width } \\
(\mathrm{mm})\end{array}$ \\
\hline 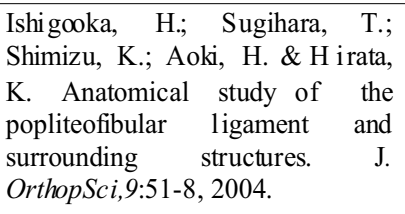 & $61.0 \pm 4.7$ & $\begin{array}{l}\text { Midportion } \\
4.2 \pm 1.1\end{array}$ & $40.4 \pm 5.9$ & $\begin{array}{l}\text { Over the PF } \\
\text { branching } \\
\text { region: } \\
7.5 \pm 1.3\end{array}$ & $\begin{array}{c}\text { Anterior margin: } \\
12.7 \pm 3.6 \\
\text { Posterior border: } \\
6.8 \pm 2.8\end{array}$ & $\begin{array}{c}\text { Midportion: } \\
10.4 \pm 3.5\end{array}$ \\
\hline $\begin{array}{l}\text { Maynard, M. J.; Deng, X.; } \\
\text { Wickiewicz, T. L. \& Warren, R. } \\
\text { F. The popliteofibular ligament: } \\
\text { rediscovery of a key element in } \\
\text { posterolateral stability. Am. J. } \\
\text { Sports Med., 24(3):311-6, 1996. }\end{array}$ & $53.4 \pm 4.4$ & - & - & - & $\begin{array}{l}\text { Anterior } 14.8 \pm 2.4 \\
\text { Posterior } 11.4 \pm 3.2\end{array}$ & $10.8 \pm 2.8$ \\
\hline $\begin{array}{l}\text { Zeng, S. X.; Wu, G. S.; Dang, R. } \\
\text { S.; Dong, X. L.; Li, H. H.; Wang, } \\
\text { J. F.; Liu, J.; Wang, D.; Huang, H. } \\
\text { L. \& Guo, X. D. Anatomic study } \\
\text { of popliteus complex of the knee } \\
\text { in a Chinese population. Anat. Sci. } \\
\text { Int., 86(4):213-8, 2011. }\end{array}$ & - & - & $38.15 \pm 5.15$ & $6.32 \pm 1.09$ & $10.23 \pm 2.36$ & $8.80 \pm 2.85$ \\
\hline $\begin{array}{l}\text { Osti, M.; Tschann, P.; Künzel, K. } \\
\text { H. \& Benedetto, K. P. } \\
\text { Posterolateral corner of the knee: } \\
\text { microsurgical analysis of anatomy } \\
\text { and morphometry. Orthopedics, } \\
\text { 36(9):e1114-20, 2013. }\end{array}$ & $61.69 \pm 3.95$ & $\begin{array}{l}\text { Midportion: } \\
5.47 \pm 1.14\end{array}$ & $36.36 \pm 4.53$ & $\begin{array}{l}\text { Midportion: } \\
8.40 \pm 1.31\end{array}$ & $\begin{array}{l}\text { Anterior: } \\
14.06 \pm 3.20 \\
\text { Posterior: } \\
12.45 \pm 2.21\end{array}$ & $\begin{array}{l}\text { Insertion: } \\
6.59 \pm 1.69 \\
\text { Midportion: } \\
7.04 \pm 2.31\end{array}$ \\
\hline $\begin{array}{l}\text { Jung, G. H.; Kim, J. D. \& Kim, H. } \\
\text { Location and classification of } \\
\text { popliteus tendon's origin: } \\
\text { cadaveric study. Arch. Orthop. } \\
\text { Trauma Surg., 130(8):1027-32, } \\
2010 .\end{array}$ & 53 & $\begin{array}{l}\text { At the level of } \\
\text { the articular } \\
\text { knee joint: } 9\end{array}$ & 36 & $\begin{array}{l}\text { At the level of } \\
\text { the articular } \\
\text { line: } 8\end{array}$ & - & - \\
\hline $\begin{array}{l}\text { LaPrade, R. F.; Ly, T. V.; } \\
\text { Wentorf, F. A. \& Engebretsen, L. } \\
\text { The posterolateral attachments of } \\
\text { the knee: a qualitative and } \\
\text { quantitative morpholog ic analysis } \\
\text { of the lateral collateral ligament, } \\
\text { popliteus tendon, popliteofibular } \\
\text { ligament, and lateral } \\
\text { gastrocnemius tendon. Am. J. } \\
\text { Sports Med., 31(6):854-60, } 2003 \text {. }\end{array}$ & 69.6 & - & 54.5 & - & - & \\
\hline $\begin{array}{l}\text { Espregueira-Mendes, J. \& da } \\
\text { Silva, M. V. Anatomy of the } \\
\text { lateral collateral ligament: a } \\
\text { cadaver and histological stud y. } \\
\text { Knee Surg. Sports Traumatol. } \\
\text { Anthrosc., 14(3):221-8, } 2006 .\end{array}$ & $63.1 \pm 5.2$ & $\begin{array}{l}\text { At the level of } \\
\text { the articular line } \\
\text { of the knee } \\
\text { joint: } 8.5 \pm 2.2\end{array}$ & - & - & - & - \\
\hline Our study & $59.76 \pm 5.58$ & $\begin{array}{l}\text { Upper part: } \\
9.50 \pm 1.99 \\
\text { Middle part: } \\
7.05 \pm 1.58 \\
\text { Lower part: } \\
5.48 \pm 1.96\end{array}$ & $43.74 \pm 8.30$ & $\begin{array}{c}\text { Upper part: } \\
12.41 \pm 2.69 \\
\text { Middle part: } \\
9.08 \pm 2.17\end{array}$ & $8.56 \pm 1.95$ & $8.99 \pm 3.84$ \\
\hline
\end{tabular}


Popliteofibular ligament: Zhang et al., pointed out the importance of the anatomical features of PF regarding reconstruction procedures. Morphometric features (Table II) and insertion sites of PF on PT and FH have been mentioned in several studies. However, there is still conflict in the literature about the PF and $\mathrm{AL}$ description. $\mathrm{PF}$ has been described as consisting of one or two parts by different authors (Maynard et al.; Ullrich et al.; LaPrade et al.; Ishigooka et al.; Kurtog lu et al.). The ligament, previously mentioned by some authors as superficial part of PF, has been discerned by the others (Ishigooka et al.; Minowa $e t$ al.; Kurtog `lu et al.) as a part of AL regarding the developmental story and attachment sites of the structure. Accordingly, in the present study, PF has been evaluated by taking into account the guidance of Kurtoglu et al.

During the fibular based reconstruction techniques and all arthroscopic techniques, fibular insertion site of PF is needed to be estimated (Niki et al.; Song et al., 2015). LaPrade et al., reported that most of the attachment sites of $\mathrm{PF}$ at the FH were on the posteromedial slope of SP, $1.6 \mathrm{~mm}$ to the apex of SP and along a distance of $5.8 \mathrm{~mm}$. Zhang $e t$ $a l$., used those anatomical data in their surgical operations. They indicated that distinguishing the attachment site ofthe injured PF during the operation and performing the graft to this point may increase the success in fixing the instability. In the present study, in most of the cases, PF was attached to the SP and/or posterior slope similar to literature, while in the 5 cases it was attached to the anterior slope of SP.

The attachment site of $\mathrm{PF}$ on popliteus musle/tendon was noted as PMTJ by (LaPrade et al. \& Zeng et al.) described the attachment site in three types as on the PMTJ, just proximal to this line and distant to the PMTJ. However, any reported case similar to our two cases, which PF attached totally to the muscular part of the popliteus has not been described. We also statistically revealed the fact that as PF attached anteriorly on FH, it also attached anteriorly on PT $(\mathrm{p}=0.001)$. Shifting of both FH and PF (as a remnant of a part of PT) together during the fetal development (Covey) could help to explain this finding.

Data about the shape of PF which could reflect to the biomechanical features of the ligament is poor in the literature. The shape of PF has been presented by Maynard et al., as trapezoidal. Accordingly, 14 of our cases had a band shape PF. While, in the 5 cases, it was in truncated cone and in only one case it was in reverse truncated cone shape. Additionally, negative correlations of PF width with length and thickness which were revealed in the present study have not been mentioned previously.

\section{CONCLUSIONS}

Detailed morphometric data of the most important posterolateral corner structures of the knee were explored with a surgical perspective. When assessing cross-sectional images of LCL, PT and PF on the MRI, it should be kept in mind that their dimensions may vary at different levels. Difference in dimensions at the upper and lower parts of LCL and formation of bursa around the ligament should be taken together into account as the factors possibly affecting the biomechanical properties of the ligament. Togetherness of the narrower inferior part of LCL with the presence of vagina synovialis formation and the more intensely fusion of the ligament with the intermediate part of biceps tendon are proposed as remarkable findings for both surgical and biomechanical viewpoints.

KURTOGLU, Z.; ELVAN, O; AKTEKIN, M. \& ÇOLAK, M. Características morfológicas del tendón del músculo poplíteo y ligamentos popliteofibular y colateral fibular. Int. J. Morphol., 35(1):62-71, 2017.

RESUMEN: El objetivo de este trabajo consistió en descubrir las características morfológicas detalladas del ligamento colateral fibular, del tendón del músculo poplíteo (TMP), del ligamento popliteofibular y de los componentes sinoviales relacionados con la obtención de datos para la aplicación quirúrgica y biomecánica. Se disecaron bilateralmente rodillas de 10 cadáveres de sexo masculino fijados con formalina. Se identificó la bursa alrededor del ligamento colateral fibular y la relación del tendón del músculo poplíteo con el ligamento colateral fibular en el sitio de la inserción femoral. La relación posicional entre ambos extremos del ligamento popliteofibular se evaluó estadísticamente. El TMP excedió el margen anterior del ligamento colateral fibular en 11 casos, el margen posterior del ligamento colateral fibular en 3 casos y superó los márgenes anterior y posterior del ligamento colateral fibular en 5 casos. La forma del ligamento colateral fibular fue más estrecha en la porción inferior que en la porción superior en 14 casos. El ancho de la porción inferior del ligamento colateral fibular fue más estrecha en los casos con bursa del tipo vaina (vagina synovialis). La relación entre ambos extremos del ligamento popliteofibular fue la siguiente: cuanto más anteriormente se localizó la inserción de la cabeza fibular, más anteriormente el ligamento popliteofibular se unió al TMP. Para intervenir el ángulo posterolateral de la rodilla con respecto a la anatomía quirúrgica y la biomecánica, se deben evaluar las características morfométricas individuales y concertadas del ligamento colateral fibular, el TMP y el ligamento popliteofibular, junto con las estructuras sinoviales correspondientes.

lla.

PALABRAS CLAVE: Ligamento colateral fibular; Tendón del músculo poplíteo; Ligamento popliteofibular; Sinovial; Rodi- 


\section{REFERENCES}

Bartonícek, J. Rare bilateral variation of the popliteus muscle: anatomical case report and review of the literature. Surg. Radiol. Anat., 27(4):347$50,2005$.

Brinkman, J. M.; Schwering, P. J.; Blankevoort, L.; Kooloos, J. G.; Luites, J. $\&$ Wymenga, A. B. The insertion geometry of the posterolateral corner of the knee. J. Bone Joint Surg. Br., 87(10):1364-8, 2005.

Covey, D. C. Injuries of the posterolateral corner of the knee. J. Bone Joint Surg. Am., 83(1):106-18, 2001.

Djian, P. Posterolateral knee reconstruction. Orthop. Traumatol. Surg. Res., 101(1 Suppl.):159-70, 2015.

Espregueira-Mendes, J. \& da Silva, M. V. Anatomy of the lateral collateral ligament: a cadaver and histological study. Knee Surg. Sports Traumatol. Arthrosc., 14(3):221-8, 2006.

Feipel, V.; Simonnet, M. \& Rooze, M. The proximal attachments of the popliteus muscle: a quantitative study and clinical significance. Surg. Radiol. Anat., 25(1):58-63, 2003.

Guha, A. R.; Gorgees, K. A. \& Walker, D. I. Popliteus tendon rupture: a case report and review of the literature. Br. J. Sports Med., 37(4):358-60, 2003.

Hash, W. T. Magnetic resonance imaging of the knee. Sports Health, 5(1):78107, 2013.

Ishigooka, H.; Sugihara, T.; Shimizu, K.; Aoki, H. \& Hirata, K. Anatomical study of the popliteofibular ligament and surrounding structures. J. Orthop. Sci., 9(1):51-8, 2004.

James, E. W.; LaPrade, C. M. \& LaPrade, R. F. Anatomy and biomechanics of the lateral side of the knee and surgical implications. Sports Med. Arthrosc., 23(1):2-9, 2015.

Jung, G. H.; Kim, J. D. \& Kim, H. Location and classification of popliteus tendon's origin: cadaveric study. Arch. Orthop. Trauma Surg., 130(8):1027$32,2010$.

Kim, J. G.; Ha, J. G.; Lee, Y. S.; Yang, S. J.; Jung, J. E. \& Oh, S. J. Posterolateral corner anatomy and its anatomical reconstruction with single fibula and double femoral sling method: anatomical study and surgical technique. Arch. Orthop. Trauma Surg., 129(3):381-5, 2009.

Kurtoglu, Z.; Elvan, Ö.; Aktekin, M. \& Çolak, M. A descriptive and morphometric study of the fabellofibular, arcuate popliteal and popliteofibular ligaments. Anatomy, 9(2):51-9, 2015.

LaPrade, R. F. \& Hamilton, C. D. The fibular collateral ligament-biceps femoris bursa. An anatomic study. Am. J. Sports Med., 25(4):439-43, 1997.

LaPrade, R. F.; Ly, T. V.; Wentorf, F. A. \& Engebretsen, L. The posterolateral attachments of the knee: a qualitative and quantitative morphologic analysis of the fibular collateral ligament, popliteus tendon, popliteofibular ligament, and lateral gastrocnemius tendon. Am. J. Sports Med., 31(6):854$60,2003$.

Maynard, M. J.; Deng, X.; Wickiewicz, T. L. \& Warren, R. F. The popliteofibular ligament: rediscovery of a key element in posterolateral stability. Am. J. Sports Med., 24(3):311-6, 1996.

Minowa, T.; Murakami, G.; Suzuki, D.; Uchiyama, E.; Kura, H. \& Yamashita, T. Topographical histology of the posterolateral corner of the knee, with special reference to laminar configurations around the popliteus tendon: a study of elderly Japanese and late-stage fetuses. J. Orthop. Sci., 10(1):4855, 2005.

Niki, Y.; Matsumoto, H.; Otani, T.; Enomoto, H.; Toyama, Y. \& Suda, Y. A modified Larson's method of posterolateral corner reconstruction of the knee reproducing the physiological tensioning pattern of the lateral collateral and popliteofibular ligaments. Sports Med. Arthrosc. Rehabil. Ther. Technol., 3(4):21, 2012.

Osti, M.; Tschann, P.; Künzel, K. H. \& Benedetto, K. P. Posterolateral corner of the knee: microsurgical analysis of anatomy and morphometry. Orthopedics, 36(9):e1114-20, 2013.

Pansky, B. \& Gest, T. R. Lippincott's Concise Illustrated Anatomy. Vol. 1: Back, Upper Limb \& Lower Limb. Philadelphia, Lippincott Williams \& Wilkins, 2011. P.261.
Recondo, J. A.; Salvador, E.; Villanúa, J. A.; Barrera, M. C.; Gervás, C. \& Alústiza, J. M. Lateral stabilizing structures of the knee: functional anatomy and injuries assessed with MR imaging. Radiographics, 20 Spec. No.:S91-102, 2000.

Seebacher, J. R.; Inglis, A. E.; Marshall, J. L. \& Warren, R. F. The structure of the posterolateral aspect of the knee. J. Bone Joint Surg. Am., 64(4):53641, 1982.

Song, G. Y.; Zhang, H.; Zhang, J.; Li, Y. \& Feng, H. Anatomical popliteofibular ligament reconstruction of the knee joints: an all-arthroscopic technique. Knee Surg. Sports Traumatol. Arthrosc., 23(10):2925-9, 2015.

Song, Y. B.; Watanabe, K.; Hogan, E.; D’Antoni, A. V.; Dilandro, A. C.; Apaydin, N.; Loukas, M.; Shoja, M. M. \& Tubbs, R. S. The fibular collateral ligament of the knee: a detailed review. Clin. Anat., 27(5):78997, 2014.

Takeda, S.; Tajima, G.; Fujino, K., Yan, J.; Kamei, Y.; Maruyama, M.; Kikuchi, S. \& Doita, M. Morphology of the femoral insertion of the lateral collateral ligament and popliteus tendon. Knee Surg. Sports Traumatol. Arthrosc., 23(10):3049-54, 2015.

Tyler, P.; Datir, A. \& Saifuddin, A. Magnetic resonance imaging of anatomical variations in the knee. Part 1: ligamentous and musculotendinous. Skeletal. Radiol., 39(12):1161-73, 2010.

Ullrich, K.; Krudwig, W. K. \& Witzel, U. Posterolateral aspect and stability of the knee joint. I. Anatomy and function of the popliteus muscle-tendon unit: an anatomical and biomechanical study. Knee Surg. Sports Traumatol. Arthrosc., 10(2):86-90, 2002.

Zeng, S. X.; Wu, G. S.; Dang, R. S.; Dong, X. L.; Li, H. H.; Wang, J. F.; Liu, J.; Wang, D.; Huang, H. L. \& Guo, X. D. Anatomic study of popliteus complex of the knee in a Chinese population. Anat. Sci. Int., 86(4):213-8, 2011.

Zhang, H.; Feng, H.; Hong, L.; Wang, X. S. \& Zhang, J. Popliteofibular ligament reconstruction for posterolateral external rotation instability of the knee. Knee Surg. Sports Traumatol. Arthrosc., 17(9):1070-7, 2009.

\author{
Corresponding author: \\ Zeliha Kurtoglu \\ Mersin University Faculty of Medicine \\ Department of Anatomy \\ Çiftlikköy Campus, 33343 \\ Yenisehir, Mersin \\ TURKEY
}

Telephone: +9032436100 01-1089
Fax: $\quad+903243610015$

E-mail: zkurtoglu@yahoo.com

Received: 25-08-2016

Accepted: $14-11-2016$ 